\title{
O vocabulário regional do escritor Ariano Suassuna na obra Farsa da Boa Preguiça
}

\author{
The regional vocabulary of the witer Ariano Suassuna in the work Farsa da Boa \\ Preguiça \\ Uélida Dantas de Oliveira* \\ Universidade Federal da Paraíba \\ João Pessoa, Paraíba, Brasil. \\ Maria do Socorro Silva de Aragão** \\ Universidade Federal da Paraíba/Universidade Federal do Ceará \\ João Pessoa, Paraíba, Brasil.

\begin{abstract}
Resumo: Nesta pesquisa apresentamos um estudo léxico-semântico das expressões regionais que fazem parte da linguagem usada pelo escritor Ariano Suassuna. Objetivamos analisar as escolhas lexicais do autor na obra Farsa da Boa Preguiça (2014), com a intenção de elaborar um vocabulário, no qual explanamos as expressões selecionadas na obra, suas definições conforme confirmam os dicionários de língua portuguesa e os dicionários de expressões regionais nordestinos. Para o desenvolvimento do estudo usaremos como fundamentação teórica o léxico e suas ciências, visando o auxílio na elaboração do vocabulário e refletindo a respeito do falar regional, considerando que a linguagem utilizada por Ariano Suassuna é um reflexo da interação entre sociedade e cultura. Sendo assim, a apresentação do conteúdo lexical presente na obra por meio de um vocabulário torna possível a compreensão da relação sociedade e cultura que transfere para a linguagem do indivíduo o reflexo da sua influência.
\end{abstract}

Palavras-chave: Vocabulário. Ariano Suassuna. Linguagem regional.

Abstract In this research we present a lexical-semantic study of the regional expressions that are part of the language used by the writer Ariano Suassuna. We aim to analyze the lexical choices of the author in the work Farsa da Boa Preguiça (2014), with the intention of elaborating a vocabulary, in which we explain the expressions selected in the work, their definitions as confirmed by the dictionaries of Portuguese language and the regional expression dictionaries of the Northeastern. For the development of the study we will use as theoretical foundation the lexicon and its sciences, aiming at the aid in the elaboration of the vocabulary and reflecting on the regional talk, considering that the language used by Ariano Suassuna is a reflection of the interaction between society and culture. Thus, the presentation of the lexical content present in the work through a vocabulary makes possible the understanding of the relation society and culture that transfers to the language of the individual the reflection of its influence.

Keywords: Vocabulary. Ariano Suassuna. Regional language.

\footnotetext{
*Mestra em Letras pelo programa de Pós-Graduação em Letras- PPGL da Universidade Federal da Paraíba, João Pessoa, Paraíba, Brasil. E-mail: uelida1114@hotmail.com.

**Pós-Doutorado na Universidad Complutense de Madrid (1976/1978). Pós-Doutorado na Central Connecticut State University - USA (1989/1990). Atualmente, é Professora Visitante Titular da Universidade Federal do Ceará e Professora Voluntária Titular da Universidade Federal da Paraíba. Tem experiência nas áreas de Linguística e Literatura, com ênfase em Sociolinguística, Dialetologia e Geolinguística, atuando principalmente nos seguintes temas: Dialetologia, Atlas Linguísticos, Falares Regionais, Fonética e Fonologia, Língua Portuguesa e Literatura Regional. João Pessoa, Paraíba, Brasil. Email: acaragao@terra.com.br.
} 


\section{CONSIDERAÇÕES INICIAIS}

O presente estudo desenvolve uma análise do vocabulário do escritor paraibano Ariano Suassuna por meio da sua obra Farsa da Boa Preguiça (2014) com o objetivo de apresentar um glossário com as expressões regionais utilizadas pelo escritor.

Através desse vocabulário constataremos a influência do falar regional, da cultura e da sociedade na qual, o escritor estava inserido, refletindo na maneira como Suassuna realizou suas escolhas lexicais e concebeu sua linguagem literária.

A obra Farsa da boa preguiça possui personagens que apresentam estilos de vida distintos, representam contextos sociais diferentes, uns ricos e outros pobres, uns aparentam ter nível de escolaridade mais relevante do que outros. E estes fatores motivam a diferença na linguagem utilizada pelo escritor para representar cada classe sociocultural no enredo de sua obra. De acordo com Vilela (1994, p. 6): "O léxico é a parte da língua que primeiramente configura a realidade linguística e arquiva o saber linguístico duma comunidade".

Considerando que o léxico permite que a pessoa ou a comunidade nomeei objetos e situações que fazem parte da sua rotina, da sua vivência conforme os costumes da sua cultura, as tradições e o contexto social em que vive, gerando assim, uma somatória de fatores que causam reflexo no modo de falar e de escrever de determinada comunidade linguística. Dessa forma ocorre na obra de Ariano Suassuna, que exibe em sua história o contexto cultural nordestino brasileiro, fazendo referência ao sertanejo, ao ambiente do sertão do Nordeste brasileiro. Isso resulta da influência da cultura e da sociedade na qual o escritor fazia parte. Como acrescenta Saussure (1996, p.221): o léxico "é um fenômeno de uma lingua que sofre variação ao longo do tempo, do espaço geográfico, de espaço ou estrutura social, da situação ou contexto de uso."

Diante do exposto, a obra em questão foi analisada com a intenção de selecionar expressões regionais nordestinas, visando mostrar através do vocabulário que Ariano Suassuna faz uso, uma linguagem que permite que o leitor de sua obra tenha contato com um pouco da cultura e dos costumes da região Nordeste do Brasil, por meio das palavras e expressões linguísticas típicas do falar regional nordestino que o escritor expõe em Farsa da Boa Preguiça (2014).

\section{ARIANO SUASSUNA}

O escritor Ariano Suassuna, autor da obra Farsa da boa preguiça e tantas outras obras de renome a exemplo do $O$ Auto da Compadecida e O Romance da Pedra do Reino, que tiveram destaque também na mídia, com minissérie e filme transmitidos ao público. Ariano Suassuna nasceu na Paraíba em 16 de junho de 1927, especificamente na cidade de João Pessoa. Porém, ainda na infância mudou-se para a cidade de Taperoá no cariri paraibano, onde viveu por alguns anos com sua mãe e seus irmãos.

Em 1946, já residindo no estado de Pernambuco e cursando Direito na faculdade de Direito do Recife, Ariano Suassuna conheceu um grupo de jovens estudantes, que 
apreciava o teatro e as artes. Um desses jovens tornou-se um grande amigo do escritor, era Hermilo Borba Filho, com quem instituiu o Teatro de Estudantes do Pernambuco.

Fundador do Movimento Armorial de 1970, movimento que tinha o objetivo de valorizar a cultura e a arte nordestina brasileira, buscando nortear para o êxito desse objetivo todas as formas de expressões artísticas como a música, o teatro, a literatura e as artes como pinturas e xilogravuras, entre outras expressões. Suassuna foi membro da Acadêmica Brasileira de Letras, secretário da cultura do Estado de Pernambuco. Autor de muitas obras que transparecem a riqueza cultural e as tradições do Nordeste, Ariano Suassuna veio a falecer em julho de 2014.

\section{FARSA DA BOA PREGUIÇA}

A obra A Farsa da Boa Preguiça, do escritor e dramaturgo Ariano Suassuna foi escrita em 1960, e apresentada no Teatro de Arena do Recife em 1961, pelo Teatro Popular do Nordeste, grupo de teatro dirigido pelo amigo de Suassuna, Hermilo Borba Filho.

Farsa da Boa Preguiça (2014) traz uma história passada em cenários do sertão nordestino brasileiro, e destaca a religiosidade e o humor, como é de costume constatarmos nas as obras de Ariano Suassuna. Porém, apesar da presença humor um fator característico do autor, a obra aborda temas como a pobreza, a humildade e avareza que despertam reflexões.

Escrita em três atos, e baseada em histórias populares, por exemplo o primeiro ato tem como base uma notícia de jornal e uma história tradicional de mamulengos, em seguida, o segundo ato , apresenta a história de um macaco que perde tudo o que ganha em negociações e apostas, após realizar muitas trocas, e o terceiro ato é fundamentado num conto popular, e também na peça de mamulengos intitulada, o rico avarento.

\section{LÉXICO E A LINGUAGEM REGIONAL}

O léxico é um fenômeno linguístico da língua que proporciona ao usuário de uma língua a oportunidade de registrar objetos e seres conforme sua visão de mundo, seus costumes culturais e o seu contexto socioeconômico. A maneira como uma comunidade ou grupo utiliza-se, chama ou classifica determinas coisas ou acontecimentos são a forma como o léxico de uma língua é gerado. Conforme Aragão (2008) "toda a visão de mundo, a ideologia, os sistemas de valores e as práticas socioculturais das comunidades humanas são refletidas em seu léxico.”.

Os processos sociais e culturais em que o sujeito ou grupo estão inseridos realizam influência em sua linguagem e nos permite identificarmos por meio do falar regional a estrutura socioeconômica, o nível de escolaridade, o seu gênero, a região geográfica na qual reside. Como relatam Villalva e Silvestre (2014): 
O Léxico de cada falante, que é também chamado de Léxico mental, depende da sua apropriação dos estímulos lexicais a que é exposto, e, portanto, variará muito em função da sua experiência linguística individual, do que ouve, do que lê, do que fala e do que escreve. (VILLALVA \& SILVESTRE, 2014, p. 23)

No campo dos estudos linguísticos, o léxico é visto como um elemento cultural que transpassa a relação existente entre o homem e a sociedade. Ou seja, o léxico mostra um conjunto de aquisições culturais provenientes de experiências sociais do homem, é o resultado de suas vivências sociais, como afirma Nunes (2013):

[...] o léxico de uma língua reflete o repositório de experiências seculares das comunidades que a utilizaram e a utilizam, de forma que o léxico se constitui de unidades criadas a partir da necessidade de interação com o universo sociocultural. (NUNES, 2013, p.18)

Dessa forma, o léxico retrata tudo o que os indivíduos consideram importante, seus interesses, costumes, e as atividades que desenvolvem, como também suas crenças. Ou seja, demonstra o modo como a comunidade vive e como os seus membros se organizam. Biderman (2001, p. 179), corrobora, dizendo: "Qualquer sistema léxico é a somatória de toda experiência acumulada de uma sociedade e do acervo da sua cultura".

Cabe frisar, que a teoria do léxico possui duas ciências que são a lexicologia e a lexicografia, ciências que são responsáveis por analisar a língua e organizar em vocabulários, glossários e dicionários de diversos tipos.

As ciências distinguem-se por meio dos fundamentos teóricos e metodológicos, a lexicologia estuda o universo de palavras, levando em consideração sua estrutura, sua finalidade e as variações. Ferreira (1997) explica que:

A lexicologia é o estudo do vocabulário geral das línguas. Esta disciplina aborda o estudo científico do léxico a partir de suas estruturas e regularidades morfológicas e semânticas. Sua principal tarefa é a definição de conjuntos de léxicos e a sistematização dos processos de criação e renovação lexicais. (FERREIRA, 1997, p. 6)

A lexicografia quanto a ela se ocupa da classificação, dos procedimentos, e das técnicas que usam o léxico como os dicionários e diversas obras lexicográficas, como assevera Barbosa (1980):

A lexicografia compreende também um discurso científico modalizado pelo $<<$ saberfazer $>>$, define-se como técnica de tratamento da lexia ocorrência, de compilação, de classificação de que resulta a produção de dicionários (monolíngues, bilíngues, plurilíngues, analógicos,...), de enciclopédias, de glossários, de vocabulários de frequência, de vocabulários específicos,... (BARBOSA, 1980, p. 56)

É válido salientar, que com o embasamento teórico das ciências do léxico é possível averiguarmos também os falares regionais, com a intenção de elaborarmos glossários e vocabulários regionais, uma vez que os falares regionais transparecem os costumes e hábitos relacionados a cultura de um povo ou comunidade linguística que usam determinado falar regional. Como esclarece Baylon (1991, p.47) "a língua pode revelar os modos de vida e os valores culturais de uma sociedade [...]”. Isto posto, fica 
confirmado mais uma vez, a existência da relação indissociável de língua, cultura e sociedade.

Diante do que foi exposto, apresentamos na próxima sessão o vocabulário da obra Farsa da Boa Preguiça (2014), com base na vivência do escritor Ariano Suassuna diante da cultura regional nordestina.

\section{O VOCABULÁRIO REGIONAL NA OBRA FARSA DA BOA PREGUIÇA}

Tomando por embasamento teórico a teoria do Léxico e as suas ciências, Lexicologia e Lexicografia as palavras foram examinadas e organizadas em macrocampos e microcampos, com base no que assevera de Coseriu (1977) em relação a língua e a sua estruturação em campos léxico-semânticos, como percebe-se na citação a seguir:

um paradigma léxico que resulta da repartição de um conteúdo léxico contínuo entre diferentes unidades dadas na língua como palavras e que se opõem de maneira imediata umas a outras, por meio de traços distintivos mínimos. (COSERIU, 1977, p. 146)

Diante disto, o vocabulário foi elaborado seguindo alguns critérios: as palavras foram divididas por categorias em macrocampos, os macrocampos são subdivididos em microcampos, as palavras são apresentadas em ordem alfabética dentro de cada macrocampo e destacadas em negrito. Seus significados constam nos dicionários de língua portuguesa e em dicionários de expressões regionais. Serão seguidas das abonações da obra analisada, estas abonações são destacadas em negrito e em itálico.

\section{MACROCAMPO: Extraordinário \\ MICROCAMPO: Causa admiração.}

Amolestada: Sf . Expressa o sentido de algo que causa admiração.

Amolestada- SF- Trata-se de uma variação da lexia Moléstia- SF- 1- Epidemia. 2-

Hidrofobia. 3- Irritabilidade. Da Moléstia - Coisa extraordinária, de causar admiração, reprovação, terror etc. (CABRAL, 1982, p. 527).

"Que piteira comprida amolestada! Isso é que é uma piteira arretada! Chega a ter meio metro?” (SUASSUNA, 2014, p. 88)

Aprumando: Adj. Sentido de organização.

Aprumado- Adj. 1- Em boa situação financeira, quase rico. 2- Equilibrado nos negócios e na vida particular. "...trabalhar, sempre aprumado nos negócios" (FMR171). 3- Empregar certa atividade com equilíbrio e segurança. (CABRAL, 1982, p. 52).

"Ainda não está tão rico, não, mas vai se aprumando. O homem é uma fera para trabalhar!” (SUASSUNA, 2014, p. 133) 
Danou-se: V. Expressão referente a uma situação espantosa, que desperta admiração ou aflição.

V. Danou-se - Interjeição de espanto, de aflição. "Danou-se! Valha-me Deus!"

(LMS 175). (CABRAL, 1982, p.271)

"Tudo isso a senhora faz? Danou-se!" (SUASSUNA ,2014, p. 88)

Demorosa: Adj. Expressão referente ao ato de demorar.

Demora- SF- Ato ou efeito de demorar(-se); delonga. (FERREIRA, 2010, p. 225)

"Conforme! A senhora quer uma obra ligeira on uma demorosa?" (SUASSUNA ,2014, p. 91)

É quebranto!: Sm. Sentimento ou sensação de fraqueza, seja física ou espiritual.

Quebranto- SM.-Abatimento, afrouxamento de quem se sente invadido por uma influência estranha, abatimento, fraqueza. (MARTINS, 2001, p. 404)

"É quebranto! Passa logo! Nevinha está começando a desconfiar do marido por causa de certas coisas que andou assistindo aqui!" (SUASSUNA ,2014, p. 159)

MACROCAMPO: Comportamento

MICROCAMPO: Personalidade e características

Cabrito sem-vergonha: Sm. Refere-se a pessoa que expressa atitudes ousadas.

Cabrito- SM- Menino, molecote. Garoto atrevido. (CABRAL, 2012, p. 152). Sem-vergonho- É o mesmo que homem sem-vergonha. (NAVARRO, 2004, p. 315)

"Vida velha desmantelada, o quê, seu cabrito sem-vergonha?" (SUASSUNA, 2014, p. 115)

Cão Coxo: Sm. Pessoa que faz coisas más, toma atitudes ruins para com outro.

Cão-coxo- SM- O demônio. "Houve um samba tão grande no inferno que cão-coxo quebrou a outra perna" (AFE 177). "As que raspam sobrancelhas e fazem com tinta preta, Satanás manada Cão Coxo espertar na baioneta" (LC 2904). "Torcida de Satanaz diz que o jogo está perido, porque Cão Coxo não joga, Satanaz está contundido" (LC 7762). "Pras profundas do inferno Roberto foi rebatado, para servir de cavalo para Cão Coxo andar montado" (LC 102016). (CABRAL, 1982, p. 182)

"O moleque do Cão Coxo, disfarçado de Frade, acabou com o dinheiro do Rico e, em troca, um peru deixou.” (SUASSUNA ,2014, p. 133) 
Feio que nem a peste: Fraseologia. Homem de má aparência, sem beleza. Feio- Adj.- 1- sem beleza; disforme. 2- fig. que inspira desprezo, nojo, vergonha; desonesto. 3- Fig. difícil de suportar; desventuroso. 4- fig. Grave, sério (HOUAISS,2012, p. 355).

Peste- SF- 1- A peste bubônica. 2- Coisa ruim, indesejável, desagradável, incômoda, excessiva. 3- Referência a um animal ou coisa qualquer. 4- Coisa de causar admiração, entusiasmo. SM- SF- 5- Individuo ruim, patife, tratante, canalha. 6- Referência a determinada pessoa, com ou sem intenções insultuosas, dando, às vezes, até sentido afetuoso. (CABRAL, 1982, p. 601)

"A única coisa que Joaquim Simão faz é tocar viola e cantar besteira e bendito! E é feio que nem a peste!” (SUASSUNA ,2014, p. 59)

Ossudos: Adj. M. Referente a magreza.

Só o couro e os ossos (ou no couro e no osso) - Magro, esquelético. (CABRAL, 1982, p. 555)

"Como vai, com esse corpo, com esses braços tão compridos, tão angulosos e ossudos?" (SUASSUNA, 2014, p. 146)

\section{MACROCAMPO: Sentimentos}

MICROCAMPO: Atos diversos, que expressam da alegria a raiva.

Azucrinar: V. Sentido de perturbação.

Azucrinar- Vtd.- Aperrear, atormentar, importunar, apoquentar. "Zefa, tu num me azucrina. Num me aperreia, muié.” (ALD 35) (CABRAL, 1982, p. 82)

"Dona Andreza, não faça uma coisa dessa! Não me azucrine mais!" (SUASSUNA,2014, p. 60)

Bestar: V. Sentido de estar sendo feito de tolo, ou fazendo tolices.

Bestar- Vi.- 1- Imaginar tolices, divagar. "Eu fico assuntando, bestando..." (AVS 96). "Era preciso não ficar assim bestando..." (FMR 41). 2- Andar àtoa, sem rumo certo. "... que andavam bestando pelo mato" (AAF 126). 3Agir erradamente; cometer tolices. "Até que um dia compreendeu que estava bestando" (FMR 130). (CABRAL, 1982, p. 110)

"Aquilo não é amor mais não, é fome, é sede! Olhe, ele está assim, bestando, feito um armador de rede!” (SUASSUNA, 2014, p. 59)

Ela fica logo azeitada: Sint. Verbal. Ato de irritar-se, demonstrar raiva. Azeitado- 1- Turbinado, acelerado: "O carro saiu da revisão hoje, está azeitado que dá gosto!". 2- Azucrinado, brabo, da pávirada: "Vicentão: - Vá pra lá, moleque! Eu hoje amanheci azeitado! Do jeito que estou, não quero nem que olhem pra mim! Vá logo ficando de costas, viu? Olhou pra mim 
hoje, morre! Benedito: - Mas o senhor, azeitado e de mau humor exatamente quando pode desmoralizar o Cabo Rosinha e ficar com Marieta, de uma vez, sem precisão de briga?" A Pena e a Lei, Ariano Suassuna.(NAVARRO, 2004, p. 45)

"Mas, minha filha, me diga, se eu posso? Ela fica logo azeitada! Isso é que é uma freipa de mulher escorropichada!” (SUASSUNA ,2014, p. 141)

Futucar: V. O mesmo que tocar.

Futucar- V- 1- Catucar. "Quando a gente menos pensa, o diabo vem futucá" (cit. JFP 82). "Futuca ela com a vara, menino!" (CICC 257). 2Cascavilhar. “... futucando nos armários" (JAD 131). 3- Insistir, aperrear. "E ela tanto futucara, tanto xeretara, até descobrir..." (JAD 113). (CABRAL, 1982, p. 412)

"Eu sou um sujeito feio, já não sou mais rapaz, tenho lá essa sorte de uma mulher vir me futucar assim, sem quê nem mais?” (SUASSUNA ,2014, p. 117)

Lesando: V. Ato de distração.

V. Lesar- Vi.- Andar à toa. "Ainda hoje se encontram lesando pelas praias" (MLM 41). Andar lesando- O mesmo que Andar Bestando isto é, andar sem destino, distraído. Estar lesando- Achar-se distraído, abstrato. (CABRAL, 1982, p. 470).

"Isso é hora de você estar por aqui lesando e dizendo besteira?" (SUASSUNA ,2014, p. 68)

Mangar: SF. Ato de rir, de dar risada de algo ou de alguém.

Mangar- SF- Zonar, vaiar, grear, ridicularizar. "E minha força de valentia? Eu não mataria Analice. Quando apareci na rua depois daquele dia, as mulheres caçoaram de mim, mangaram abertamente, as mulheres me esquartejaram com foices e machados. Pois eu tivera medo, então, da loira? Foi o segundo dia de maior vergonha de minha vida. Foi a segunda esculhambação de mim." As mulheres de Tijucopapo, Marilene Felinto. (NAVARRO, 2004, p. 222)

"Amarrando em todos nós, a gente vai arrastar: leva pra casa do dono, que é pra rir e mangar!” (SUASSUNA, 2014, p. 100)

Ô aperreio danado: Fraseologia. Um problema complexo, ou muita dificuldade.

Aperreio- SM- 1- Privação, dificuldades, trabalheira- 2- Perigo, tribulações. (CABRAL, 1982). Danado- de grande proporção; imenso. (HOUAISS, 2012, p. 218)

"Ô aperreio danado, minha Nossa Senhora! Deixe en dormir, Nevinha!" (SUASSUNA ,2014, p. 76) 
Passar ele no bucho: Fraseologia. No sentido de alimentar-se, comer algo. Bucho- SM- 1- Estômago. A barriga. "Tô hoje com o bucho cheio, tô até meia impanzinada" (ALD 55). (CABRAL, 1982, p. 140)

"O enterro do meu canário foi coisa pra muito luxo: veio o gato da vizinha e passou ele no bucho!’ (SUASSUNA , 2014, p. 95)

MACROCAMPO: Costumes e tradições

MICROCAMPO: De uso pessoal ou coletivo

Bodoque: Sm. Uma espécie de estilingue, objeto de caça.

Bodoque - SM- Espécie de arco que lança pedrinhas ou pequenas bolas de barro cozidas ao fogo. Em vez de distender o arco com uma só fibra, corda ou cordão, usam-se dois cordões ou barbantes paralelos que vão unir-se nas extremidades do arco de madeira, deixando-o bem tenso e curvo. As extremidades desses cordões paralelos ficam separadas por dois pauzinhos denominados canários. No centro desses cordões distendidos fica a "rede" bem tecida, onde é alojado o projétil para ser desferido. "... davam caça, a bodoque, nos dias de folga" (JAB 36). "... matando rolinhas de bodoque" (FMP 33). "Armaram arapuca para pegar passarinhos, saíam a caçar com bodoque" (CICC 127). (CABRAL, 2012, p. 120)

"Sen Aderaldo está feito um bodoque: chega está todo alesado, todo besta para o mundo!” (SUASSUNA ,2014, p. 63)

Folheto e bendito: Sm. Refere-se a poesias e canções que falam de amor e sofrimento.

Bendito- SM- Cantar bendito- V. este verbete. CANTAR BENDITOSofrer. (Expressão pouco usada atualmente). "Cantar bendito é a expressão matuta que significa sofrer, padecer." (OAP 459). Folheto- SM- 1- Obra impressa de poucas páginas. 2- Fôlder. 3- Prospecto. (CABRAL, 1982, p. 180)

"Dona Clarabela, a mulher de Seu Aderaldo, é a maior entendida nessas histórias de folheto de bendito!" (SUASSUNA ,2014, p. 62)

\section{CONSIDERAÇÕES FINAIS}

O estudo analisou a linguagem de Ariano Suassuna por meio de sua obra literária intitulada Farsa da boa preguiça (2014), e exibiu o êxito de ter alcançado o resultado proposto no início do trabalho, que é o vocabulário regional do autor. Verificou-se que o vocabulário expressa a interação do conhecimento de mundo do escritor, a cultura popular, a qual, ele sempre valorizou e defendeu, e a influência social da região Nordeste, fatores que conduziram reflexos para a linguagem utilizada por Suassuna em seu vocabulário.

Em síntese, levando-se em consideração o fato relevante do escritor ser usuário da língua portuguesa, e valorizar copiosamente a cultura nordestina, sua linguagem e seus costumes, proporcionou aos leitores e admiradores de suas obras possibilidades diversas 
de conhecer o modo de vida do grupo social que vivem na região Nordeste do Brasil. A obra de Ariano Suassuna apresenta práticas sociais distintas, uma visão de crenças e tradições enraizadas a sentimentos, costumes e ao contexto socioeconômico nordestino.

\section{REFERÊNCIAS}

ARAGÃO, M. S. S. Variantes diatópicas e diastráticas na língua portuguesa do Brasil. São Paulo: PUC, 2008.

BARBOSA, M.A. Lexicologia, lexicografia, terminologia, terminográfia, identidade científica, objeto, métodos, campos de atuação. In Anais do II Simpósio Latino-Americano de Terminologia. I Encontro Brasileiro de Terminologia Técnico-Científica. Brasília: 1980. BAYLON, C. Sociolinguistique: societé, langue et discours. Paris: Nathan, 1991.

BIDERMAN, M. T. C. As ciências do léxico. In: OLIVEIRA, Ana Maria Pinto Pires de; ISQUERDO, Aparecida Negri (Orgs.). As ciências do léxico: lexicologia, lexicografia, terminologia. 2.ed. Campo Grande: UFMS, 2001.

CABRAL, T. Novo dicionário de termos e expressões populares. Fortaleza: UFC, 1982.

COSERIU, E. Hacia uma tipología de los campos léxicos. In: Princípios de semántica estructural. Vers. esp. de Marcos Martinez Her-nández, rev. por el autor. Madrid: Gredos, 1977, p. 210-242.

FERREIRA, A. B. H. Miniaurélio. Século XXI. Escola: O minidicionário da língua portuguesa/ Aurélio. Coordenação de Margarida dos Anjos e Marina Baeird Ferreira. Lexicografia de Maria dos Anjos [et al.] 4 ed. Rio de Janeiro: Nova Fronteira, 2010.

FERREIRA, R. R. Para um vocabulário semi-sistemático da cultura e da indústria da rede de dormir e um estudo dos movimentos sígnicos constitutivos de sua linguagem. Dissertação (Mestrado em Linguística). Programa de Pós-Graduação em Linguística. Universidade Federal do Ceará. Fortaleza: 1997.

HOUAISS, A. Dicionário de língua portuguesa. Rio de Janeiro: Objetiva, 2012.

MARTINS, N. S. O léxico de João Guimarães Rosa. São Paulo: Editora da Universidade de São Paulo, 2001.

MARTINS, N. S. O léxico de João Guimarães Rosa. São Paulo: Editora da Universidade de São Paulo, 2001.

NAVARRO, F. Dicionário do Nordeste: 5000 palavras e expressões. São Paulo: Estação Liberdade, 2004.

NUNES, P. C. R. Estudo do léxico policial militar. Belo Horizonte: UFMG, 2012.

SAUSSURE, F. Curso de linguística geral. Tradução de Antônio Chelini, José Paulo Paes e Izidoro Blikstein. 27. Ed. São Paulo: Cultrix, 1996. 279 p.

SUASSUNA, A. Farsa da boa preguiça. Rio de Janeiro: José Olympio, 2014.

VILELA, M. Léxico e gramática. Coimbra: Almedina, 1994.

VILLALVA, A. SILVESTRE, J. P. Introdução ao estudo do léxico: descrição e análise do Português. Rio de Janeiro: Vozes, 2014. 
Recebido em: 05/06/2017

Aprovado em: 23/07/2017

Publicado em: 01/12/2017 